\title{
Direct and indirect power ultrasound assisted pre-osmotic treatments in convective drying of guava slices
}

\begin{abstract}
Application of ultrasound to osmotic dehydration of guava slices via indirect sonication using an ultrasonic bath system and direct sonication using an ultrasonic probe system was studied. Pre-treatments were designed in three osmotic solution concentrations of 0,35 , and $70{ }^{\circ}$ Brix at indirect ultrasonic bath power from 0 to $2.5 \mathrm{~kW}$ for immersion times ranging for 20-60 min and direct ultrasonic probe amplitudes from 0 to $35 \%$ for immersion times of 6-20 min. The calculated ultrasound intensities from calorimetric ultrasound power dissipated indicated that direct sonication was more intensive than indirect sonication. The general linear model (GLM) showed that ultrasound input (power and amplitude), osmotic solution concentrations, and immersion time increased the water loss, solid gain, and total colour change of guava slices significantly with $\mathrm{P}<0.0005$. Indirect sonication in osmotic solutions contributed to high water loss and solid gain with acceptable total colour change than direct sonication. Applying ultrasound pre-osmotic treatment in $70{ }^{\circ}$ Brix prior to hot-air drying reduced the drying time by $33 \%$, increased the effective diffusivity by $35 \%$, and decreased the total colour change by $38 \%$. A remarkable decrease of hardness to $4.2 \mathrm{~N}$ obtained was also comparable to the fresh guava at $4.8 \mathrm{~N}$.
\end{abstract}

Keyword: Guava; Drying; Ultrasound pre-treatment; Fruit quality 